\title{
About to Lose all the Soil in Zaka's Ward 5, Zimbabwe: Rewards of Unsustainable Land Use
}

\author{
E.C. Makwara ${ }^{1}$ and D. Gamira ${ }^{2}$
}

\begin{abstract}
Soil erosion which manifests itself in the form of gullies, rills and sheet wash is an immensely complicated process involving the interaction of many biological, social, economic, environmental and political factors. It varies in its occurrence both spatially and temporally. The ultimate result of soil erosion is that it reduces crop yields and ruins agriculture, though the exact extent of soil erosion and land degradation is not known. The study was carried out in Masvingo Province, Zaka District, Ward 5 with 4502 households using the questionnaire survey, interview and field observations as research methods. The study established that population pressure ( people and livestock), as evidenced by, cultivation of steep slopes ,stream bank cultivation, deforestation and overstocking are major problems .From the results, it emerged that people continue to compound the problem by settling and extending farmlands on steep slopes, stream banks, grazing land and dambos/ veils. Therefore, there is need to educate people on conservation, proper tillage, proper or correct stocking rates, develop a proper land tenure system and avoiding land degradation. There are patches of abandoned land on account of failure to support crops or grazing. This means that there is need for soil conservation measures to be instituted so as to save the soil from further deterioration. This is not to say nothing has been done before, rather it is the enormity of the problem that dictates that form and decisive action needs be taken sooner rather than latter. Measures which have been implemented are fragmented and seem to have met with very limited, if at all any, success so there might be need to revisit both the approach ,methods, techniques and strategies which have been tried hitherto with a view to blend them with the yet untried and untested methods.
\end{abstract}

Key words: Soil erosion, sustainable agriculture, soil conservation, gully erosion, rill erosion and sheet wash erosion

${ }^{1}$ Lecturer in Geography at Great Zimbabwe University, Curriculum Studies Department. E-mail: enomakwara@yahoo.com Mobile; +263 0712867194/+263 773898758/+263734127836

2 Lecturer in Environmental Studies at Great Zimbabwe University, Department of Teacher Development. E-mail: dgamira.lands@gmail.com 


\subsection{Background}

Soil is one of the most important natural resources for living things, humans included. Soils however, undergo a very long formation process .In contrast, its depletion through erosion is very rapid. Whitlow (1988) contends that 1848000 hectares of land in all agro-ecological regions in Zimbabwe are eroded and an average of 76 tonnes of soil is lost per hectare through soil erosion. Erosion problems are immensely complicated, involving as they do many social, economic, environmental and political factors. In the soil erosion equation, there is an interaction of energy forces(rainfall intensity),resistive forces ( stable soil aggregates) and protective forces(plant cover). Logically where and when protective and resistive forces are low in relation to energy forces as occurs in most communal areas of Zimbabwe, high rates of erosion occur with dire consequences.

Rates of soil formation in Zimbabwe are quite low, somewhere in the order of $400 \mathrm{~kg}$ per hectare per year (Whitlow 1988). These rates have been generally accepted for a long time but more recent observations indicate that these rates may be exaggerated. These rates were the result of a survey carried out on a specific single soil type in one ecological region, thus their replicable access in a country with high variability in terms of erosive and stabilising factors is questionable.

There is neither question nor denying that soil erosion is taking place. Lal and Singh (1998) observe that unless erosion is stopped, many parts of Africa will suffer food shortages and famines. As the top soil gets removed, there is loss of nutrients which give plants the necessary requirements for proper growth. The shortage of nutrients leads to crop failure even when moisture is available (Piemental et al, 1997). Although soil erosion is a serious threat to food production, there is little, if at all any effort made to compensate nutrient loss and unfavourable physical soil properties that result from the process (Kariaga 2000). Soil erosion is such a serious problem, so conservation measures should be considered a key part of sustainable development strategies in the country rather than being treated as a token appendage. This should be understood against the background that the two most important factors which contribute to the statistical variation in erosion are soil type and human population. Whitlow (1988) found a correlation between high population density and high rates of erosion. Fragile /poor soils and high population densities have driven many areas into a full ecological disaster. Such a scenario prevails in Zimbabwe's Zaka district, ward 5 home to 4502 households in agro-ecological region three. 


\subsection{Theoretical Framework}

\section{Soil erosion}

Soil erosion involves the detachment of soil particles from larger aggregates and their transportation by water or wind from the soil mass (Kariaga, 1999) .There has been widespread and popular portrayal of a variety of causes of this crisis in Africa. However, Kariga (1999) offered useful quantitative simplification stating that soil erosion results from the dynamic interaction of energy of water or wind causing erosion (erosivity), the inherent existence of the soil system to detachment and transport (erodibility) and the protection factor or vegetation. These causes result in an imbalance between weathering and erosion with the latter exceeding the former. This means that its form gets changed from a 'renewable' to a nonrenewable resource in the absence of remedial action. Soils, like water, are the cornerstone of life as we know it. We leave in a world where more and more people are relying on increasingly smaller pieces of land. Zimbabwe, with its fixed area of $390759 \mathrm{~km} 2$ has limited land resources (Central Statistical Office [CSO] 1982, 1992, 2002). If we do not understand our land resources and the environment in which they occur, then we cannot manage them and thus we will be heading for disaster. Understanding soils for conservation, erosion control and food security is crucial since it (soil erosion) is one of Southern Africa's major environmental problems. It deserves a lot of attention. It reduces crop yields and ruins agriculture (Whitlow, 1988; Kureya web@step.26/11/2010).

\subsection{Study Area}

Zaka District is a semi-arid, mountainous area with erratic rainfall averaging 600$800 \mathrm{~mm} / \mathrm{yr}$ lying some $350+\mathrm{km}$ to the south of Harare,Zimbabwe's capital . Its soils are generally poor and its terrain is quite rugged. Subsistence farming is the main economic activity and the main crops grown are maize, groundnuts, cotton, sorghum, finger millet, sunflower,sweet potatoes and pumpkins. The population density now hovers around 72 persons per square kilometre(CSO,2002), which is quite high for an area with physical features outlined above. Hence ,environmental consequences are over-utilization of the natural resources, deforestation, severe soil erosion and environmental degradation in general.

Muroyi Communal area [Ward 5] lies in Zaka district, about $80 \mathrm{~km}$ south- east of Masvingo town, the provincial capital of Masvingo province. Five villages which cover an estimated area of 35 square kilometres constituted the study area. These are Gumbu, Matowe, Mangezi, Mavhenyengwa and Ngadzigurwe .Subsistence agriculture is the mainstay of the economy. The area experiences a tropical wet and - dry type of climate which provides moisture for plant growth in the warmer part of the year but causes moisture deficiencies and plant stress during the cooler season .Precipitation comes mainly in the form of convectional rainfall between 
November and March with a minimum of $60 \mathrm{~mm}$ in each of the five months. The peak occurs in December, which receives a mean rainfall of about $140-150 \mathrm{~mm}$. On average, about $700 \mathrm{~mm}$ of rainfall are received in this part of Zaka's ward 5 . Like rainfall, temperatures fluctuate with season. The area is therefore semi- arid and mountainous with erratic rainfall averaging $600-800 \mathrm{~m}$ per year. Soils are generally fragile yet population density has ever been rising from 40(1982) to 65 (1992) and 72(2002) (C.S.O. 1982, 1992, 2002) which is quite phenomenal for this fragile and mountainous area.

The minimum temperature of 10 degrees Celsius is experienced in July while the mean maximum temperature of 26 degrees Celsius is experienced in October (Department of Meteorological Services, 2000). The major landforms in the area are bornhardits, whalebacks, castle kopjes and granite tors. The area is largely under highly mixed deciduous woodland or occasionally bush land (Vincent, no date).Muroyi area lies in the middle veld of Zimbabwe between $600 \mathrm{~m}$ and $1320 \mathrm{~m}$ above sea level. The vegetation of the area is woodland. Trees used to be closely spaced or widely spaced with a grass cover mainly of perennial species varying inversely with tree type. These trees are intermixed with several herbaceous species and shrubs. Species diversity is higher on valley bottoms and lower mountain slopes than on upper slope mountain slopes because of the higher moisture regimes in the latter locations. (Masocha and Gandiwa, 2001)

\subsection{Causes and severity of soil erosion}

While there are universally accepted causes of erosion, there is need to look at site- specific causes of this problem as it can be attributed to lack of data necessary for showing its effects on agricultural production. This lack of data has curtailed the development of conservation practices in Zimbabwe and many African countries, in addition to compromising the use of conservation models developed elsewhere. The absence of adequate data, coupled with the lack of extension personnel, has hindered the rehabilitation of eroded land necessary for the restoration of the productive capacity of the soil. It is against such a background that this study seeks to establish the magnitude and intensity of soil erosion in Ward 5 of Zaka District. The data will facilitate the assessment erosion has on soil productivity so as to come up with recommendations on the best way forward. There is need for site -specific factors (human and physical) in soil erosion studies in order to avoid damaging assumptions regarding soil erosion. This is against the background that soil erosion is an interdisciplinary problem and that there are challenges to soil conservation in practice.(Blaikie,1985;Blaikie and Bookfield,1987,Elliot,1989).To this end, soil erosion should not be viewed in a narrow geographical and historical framework for this is dangerously myopic. The 
whole context in which decisions are made, from individual farmers and even at higher levels varies, spatially and temporally, considerably so between societies to the extent of frustrating generalisations in terms of explanation or conservation recommendations from one place to another. Only when physical and social processes combined, in the past and at present, are fully understood can contemporary patterns of soil erosion be understood. At any rate, the continued erosion of soil in any one location is a function of, not only physical factors, but, the cumulative land use decisions made by individuals within the context of their broader social, economic, political and cultural environments.

\subsection{Research methods}

The five villages were deliberately selected for the study from a total of 24 villages in Muroyi South [Ward 5].A list of all surviving old people (55 years and above) was made in consultation with village heads. This was used as a sampling frame from which 15 people ( 9 females and 6 males) were selected for interviews. The sample was $41 \%$ of the total population of the elderly people in the community. These elderly people were assumed to have knowledge of environmental changes which have occurred in their respective villages in so far as the number of households, livestock herds, field sizes, agricultural practices and productivity in the area are concerned.

A second list comprising household heads was compiled. Village heads' lists of households in areas under their jurisdiction were used as the sampling frame. A total of 45 households representing $20.4 \%$ of all households in the five (5) villages were selected and interviewed. The majority of them (63\%) were females while males accounted for the remainder (37\%). It was assumed that every household head had some knowledge about farming practices, farm sizes, livestock herd, family sizes, etc of their respective villages.

Altogether, sixty (60) respondents were interviewed. Practically all the interviewees were into subsistence farming though some were professionals in their own right (teachers, nurses, policeman soldiers etc). Females (37) accounted for 61, 67\% while males (23) constituted the remaining 38.33\%. Questionnaires were administered by the author who was born and raised in the area and was therefore known as a 'son' of the Muroyi South community whom they could trust and therefore could respond to questionnaires easily. In spite of this, farmers often expressed suspicion about the motive(s) of the researcher. Information on livestock herd, households and fields was not readily availed as farmers thought this was a census which could be passed on to the council for tax purposes. There was need therefore to liaise with kraal/village heads and the dip tank attendants in order to corroborate and verify information obtained from the interviews. The size of the field, livestock herd, farming systems and land management practices 
were recorded in the field book. Information on erosion was sought (gullies, rills, sheet wash) and conservation methods being practised were sought as well. Issues pertaining to encroachment on grazing land and dambos/vleis and productivity were also sought.

\subsection{Research findings}

\section{Population pressure and severity soil erosion}

Quite a number of issues emerged from the research. Soil erosion is quite rampant and severe in the study area. The causes that were identified as underlying and underpinning soil erosion in the area were population pressure, overstocking, cultivation of steep slopes, stream bank cultivation, overgrazing and deforestation. Issues arising from the said causes related to field boundaries, road and drain strips, field sizes, livestock herd sizes and grazing lands among others. Farmers generally perceived soil erosion to be a serious problem yet there was no significant adoption of 'technology' to combat this menace. The results show that farmers are aware of the major causes of erosion and these coincided with field observations done by the researcher and the district natural resource specialist.

Boundaries of fields, road and drain strips are ignored and many people cultivate land not allocated to them. People disregard, contravene and transgress demarcation regulations. Practically all farmers are 'illegally' extending their fields. Such a scenario is not coming as a surprise. The large population density of the ward $(72+$ people $\mathrm{km} 2)$ and shortage of cultivable land forces people to cultivate hillsides and stream banks. The latter was related to the issue of food security as is argued by Scoones et al (1996). 'Traditional leaders' authority has been seriously undermined by the introduction of a new leadership in the form of councillors who happen to be elected political leaders. It is now very difficult for villagers to take orders and or instructions from traditional leaders. Besides, traditional leaders receive bribes from some of the willing villagers who will be seeking to either extend their fields and gardens anywhere within the concerned headman's territory or to secure fields for their sons. In other words, village heads get enticed and induced into corrupt activities. Meanwhile, councillors turn a blind eye to the non-sustainable use of land for political expedience.

\subsection{Size of cultivable land}

In Zimbabwe's communal lands, like elsewhere in developing countries, the quality and quantity of land available for farm holders largely determines production. The average size of the cultivated land in the study area is 1.4ha. 


Table 1: Average size of cultivable land
\begin{tabular}{lccccc} 
Year & 1970 & 1982 & 1992 & 2002 & 2010 (estimate) \\
Field size & $5-6 \mathrm{ha}$ & $4-5 \mathrm{ha}$ & $2.3 \mathrm{ha}$ & $1.4 \mathrm{ha}$ & $1.3 \mathrm{ha}$ \\
\multicolumn{5}{c}{ (Source-Central Statistical Office, 1982, 1992 \&2002) }
\end{tabular}

Table 1 shows information on farm size changes from 1970. The table shows a decreasing trend in the size of land available for farming per household. Whereas the field size per household was on average not less than 5 hectares in the 1970s, today, the average field size is 1.4 ha hectares if not less.Clearly, the size of the field has been steadily declining. Population has increased as evidenced by the number of households in the district (C.S.O.1982, 1992, 2002 census figures). Given the fixed land area, the communal tenure system and that every male adult is entitled to land, parents apportion their fields in order to accommodate the entire spectrum of their sons. This, parents have to do because not so many people born and bred in this area migrate. There really has to be some compelling perceived utility value of the intended destination in order to overcome the resistive cultural forces for one to migrate to distant places. With respect to nutritional density, Zimbabwe is now densely overpopulated. This means that land is now being intensively utilised and is given no recovery period. Headmen also allocate arable land in grazing land, mountains and along stream banks. Indeed, in one of the villages in the study area, peasant farmers are now required to herd their livestock only around the perimeter of their fields. It is worth noting that land holdings in the study area are getting fragmented. This has a bearing on the adoption levels of conservation measures as small fields make it difficult and unsound to design the form of labour and farmers' perceived benefits (Manjoro, undated).

\subsection{Cultivation and erosion}

Ploughing is a standard seasonal agricultural practice in the area. However, ploughing increases erosion in several ways. This is particularly true if ploughing is done every year. Ploughing damages soil structure by crushing the soil (pulverising), producing large powdery material. The dust mixes with rain water to form mud. The mud seals the soil surface so that rain water can neither infiltrate nor seep/soak. This leads to increased runoff and soil loss. Besides, farmers are in the habit of dragging ploughs to and from their fields thus defining run-off routes, in addition to loosening the soil.

Secondly, ploughing reduces the amount organic matter in the soil. When soil is broken and turned over by the plough, extra air and warmth that gain entry into the soil help bacteria that is naturally present in the soil, to eat up the organic matter at a much faster rate. Much of it turns into gas meaning that it gets lost as 
it disappears into the air. As organic matter gets used up, soil particles and nutrients have nothing to cling onto and are easily washed away by rain. The soil loses its fertility and its ability to withstand erosion. Such soils, if cultivated continuously for ten or more years, become poor in condition, degraded and erodible.

\subsection{Runoff and erosion}

Cultivation is extensively undertaken in the area while vegetation, at the very best, is sparse to medium. Raindrops are the main culprits when it comes to runoffinduced erosion. Rainfall is mostly of high intensity and low duration .Quite often, it comes in thunderstorms, particularly in the early phases of the rainy season. The rains therefore are particularly violent during the infancy of the rainy season, the very time when the land would be cracked and practically bare and devoid of vegetation cover. Crop residue is either removed for storage as dry season fodder or it gets cleared by freely moving livestock from May to mid-November. It comes as no surprise that over $25 \%$ of the area is seriously eroded. The causes are mainly to do with the conditions obtaining within the area, both human and physical. Overpopulation leads to and combines with unsuitable farming practices in this ecologically fragile area which often receives short heavy downpours, in accentuating the erosion problem. This encourages rill and sheet wash erosion, particularly on steep slopes in widespread granite landscape which characterise the area. On such terrain, surface run-off is generated quickly and it increases so fast. Drops falling on a flat granular surface commonly produce small impact craters (Rice, 1977).In Southern Africa, the average drop size is such that when they hit the ground, they are travelling at about $20 \mathrm{~km} / \mathrm{hr}$. Normal raindrops attain velocities ranging from under $1 \mathrm{~m} / \mathrm{sec}(3,6 \mathrm{~km} / \mathrm{hr})$ to $9 \mathrm{~m} / \mathrm{sec}(32.4 \mathrm{~km} / \mathrm{hr})$. It is evident then that heavy thunderstorms, which are received in the area, are vastly effective as erosion agents especially at the commencement of the rainy season. The effectiveness of raindrop impact depends very much on the density of vegetation cover. A complete foliage cover prevents any dislodgement of soil particles .In the absence of vegetation, as is the case in the study area, splashes carry fine particles many millimetres from the original landing point (Rice, 1977). Besides, the cohesion of organically rich soils also acts as a break on movement. It has to be appreciated that damage begins during a typical heavy storm when the millions of raindrops bombarding each square metre of soil produce a synergy since one drop produces very little damage on its own. In this ward, like elsewhere in the country and the Southern African region, rainfall intensities of $30 \mathrm{~mm}$ $40 \mathrm{~mm}$ per hour are not unusual and bigger storms are a fact of life. Generally speaking, one millimetre of rainfall/hectare weighs 10 tonnes, therefore, the $30 \mathrm{~mm}-40 \mathrm{~mm}$ of rainfall striking bare ground at $20 \mathrm{~km} / \mathrm{hr}$ means $300-400$ tonnes. 
Raindrops dislodge individual particles of soil. The loose soil particles are easily washed away over the surface of the ground. After the heavy rains, the fine mud forms a hard crust that seals the soil surface, making it difficult for rainwater to soak. Once a crust is formed, the rain, instead of seeping into the soil, washes over it.

\subsection{Hills and Valleys}

In terms of relief the ward is quite broken to the extent that one can hardly recognise flat land. The altitude of the area is anything between $2473 \mathrm{ft}$ and $4014 \mathrm{ft}$ (Vincent, no date). According to the Federal Ministry of Agriculture (1955), the ward is covered by granite under highly deciduous mixed woodland with occasional bush land. With respect to erosion, it is therefore worse on slopes and hillsides. Even small slopes make a difference. Once run-off gets to move fast on the slopes, it knocks into other objects and causes them to move too. The steeper the slope the faster the run-off and therefore the greater the erosion.As runoff washes downhill, it picks sediment load of soil particles, sand and small stones. This gives the run-off added erosive power, like grit and sand paper, tearing up more soil particles from the ground and scouring out small channels that turn into gullies. Run-off damages agricultural land by reducing productivity in three ways namely, through 'localised' droughts, nutrient loss and soil loss. This in turn means that less water is absorbed and available for use by plants. Nutrient loss is a hidden cost of soil erosion. While we cannot see nutrients disappearing, it is the most serious impact of soil erosion. Erosion selectively removes nutrients such as nitrogen and phosphorous by removing the organic matter and clay particles. It removes more than naturally occurring soil nutrients and fertilizer as well. A Zimbabwean study of soil nutrient loss through erosion found that an erosion rate of $30 \mathrm{t} / \mathrm{ha} / \mathrm{year}$, typical of many communal subsistence farmers, removed half the applied fertilizer. The replacement of these lost nutrients at national level would cost $\$ 2.540$ million each year (the corresponding figure for South Africa would be R1000 million) (http:www.sardc.net/imercsa)

Sheet erosion (rainfall washing overland) is the most serious type of erosion. In Zimbabwe, sheet erosion is estimated to remove $50 \mathrm{t} / \mathrm{ha} /$ year from average communal land. Sheet erosion is the starting point for gully erosion. Rainfall overland flow and/ run off tends to concentrate and gouge its own channel. The steeper and the longer the slope the greater the damage. Gullies are a result rather than a cause of sheet erosion, a consequence of removing vegetation on a hillside through cultivation, burning or overgrazing. Natural drainage channels cannot handle the extra run-off caused by the reduction in vegetation. Run-off pours into drainage channels like a waterfall. The channels get undercut and scoured, dug 
deeper and wider by the storm water. Gullies and rills which are so extensive and elaborate in the ward expand even faster in years of above average rainfall especially after a period of drought when vegetation would have died. Droughts are a common feature in Zimbabwe and they are more severe and devastating in the low-lying areas of the country. It is common knowledge that Zimbabwe has experienced three droughts in three decades (1982/83; 1991/2 and 2001/2002 with the 1991/2 being the worst in the country's history). The 2010/11 season did not bring any joy either, more so in the drier southern provinces of the country where the study area lies. Rainfall was so unevenly distributed over the season that even pastures are in a very poor state of vegetation cover let alone the fields that had been ploughed in readiness for planting.

Sometimes cattle tracks or road ways and furrows provide starting points for gullies. The 5se acts as collection sites for rain, when storm water overflows and escapes it pours down the hill. In other words, they provide routes for storm water to pour down hill thus causing a gully. Though gullies look terrible, sheet erosion actually causes much more soil damage. A survey of a section of Luangwa valley on Zambia's eastern border found that where severe gulling occurred, the amount of soil removed by sheet wash was more than double that of gulling. On average, $510 \mathrm{t} / \mathrm{ha} / \mathrm{yr}$ was removed by sheet wash compare to $127 \mathrm{t} / \mathrm{ha} / \mathrm{yr}$ removed by gullies. ((http:www.sardc.net/imercsa)

Very high erosion rates were evident on bare soils. This is consistent with results of a study in Strinyanga in Tanzania which compared erosion in nearby areas and found that vegetation made all the difference. Areas with plenty of grass and trees had rates of erosion around $5 \mathrm{t} / \mathrm{ha} / \mathrm{yr}$ while areas with poor vegetation cover had erosion exceeding 100t/ha/yr (http:www.sardc.net/imercsa). This has to be understood against the background that plants protect soil from erosion in several ways. Trees, shrubs and grasses break the force of raindrops. Raindrops hit the plants first, breaking into small droplets that fall more gently to the soil surface. In addition, plant roots physically hold the soil in place. Furthermore, plants and their roots provide an environment for earthworms, ants, termites and moles. These creatures construct underground tunnels which help rainfall soak into the ground and reduce runoff. Plants that have many stems growing close together, like grass, help the soil absorb water by providing thousands of little holes through the soil surface. Also, plant stems act as little dams, slowing runoff as it flows over the land allowing more of the rain to soak into the ground. Dead plants lying (the moribund) on the surface protect the soil from the impact of rain drops and shade if from the sun. With time, the dead vegetation rots and becomes part of the soil adding organic matter which helps it absorb water. 


\subsection{Field extension}

Owing to the ever increasing population and the tenure system in practice, virgin land is being harnessed. Besides virgin land, grazing land is also being encroached upon. It has been alluded to earlier on that in one of the villages, one can only graze his/her herd close to their fields, a sign of the shortage of grazing land. Farmers are now bringing mountain slopes, vleis and grazing land under cultivation. In an effort to clear the land, grass is burnt so are trees which would be occupying land earmarked for cultivation. Even crop residue, notably cotton and millet, is burnt. By removing the vegetation, fires take away organic matter which would otherwise have improved the soil and remove protection from the rain and sun. Burning also tends to seal the soil surface. This increases resistance to water penetration which means there is less rainwater seeping into the soil and more run-off that causes soil erosion. Land pressure has become so high that marginal or unsuitable land has been and is still being brought into cultivation.

Since field extension is done at the expense of mountain slopes, vleis and grazing lands, it means there is overgrazing. This scenario is compounded by the fact that new households are also building their herds. (See next section below) Communal people have always regarded the extension of agricultural land as the sole option for increasing productivity. Since 1980, agricultural land has expanded at the expense of woodland, forest areas, grazing land and mountains. Besides providing wood fuel and building material, woodlands are also important for the provision of food in form of fruits, termites, caterpillars, honey, edible fungi, small wildlife species, traditional medicine, soil management and livestock browsing. Typically, because the ward is largely deforested, it is heavily eroded. The manner of land use is also a function of the tenure system in place. Farmers have the right to use the land (arable and grazing) but not to own it. Such land tenure arrangements are a major source of insecurity and discourage investment. Even more importantly, a 1989 survey established that $70 \%$ of the households had access to 2,5 hectares of arable land while the rest had less than 1, 5 hectares.

\subsection{Livestock ownership, overstocking and overgrazing}

Livestock is an important component of the farming system in the ward 5 as it is in many communal lands of Zimbabwe. Cattle have a multiplicity of functions in the communal areas namely draught power, provision of manure, supply of milk and meat, sale of stock to meet urgent needs and other socio-cultural factors. Due to the mult-ipurpose role of cattle, communal people are not willing to readily dispose of them. To them, cattle are a symbol of wealth, so scientific management principles are of no consequence and are thus immaterial hence conservation of land is not an issue at all. Households in the survey owned cattle, goats, sheep, donkeys and pigs not to mention fowls and other smaller livestock. Some of the 
livestock, including smaller ruminants, are sold to augment family incomes in times of need. Draught power is greatly needed in soil management and conservation such as winter ploughing, contour construction (where adopted) and many other practices. Those who own cattle are thus better resourced for farming.However, the large number of households means that there are more cattle/livestock which implies overstocking and therefore overgrazing.

Table 2: Average livestock ownership of sampled households

$\begin{array}{lccccc}\text { Livestock type } & \text { Cattle } & \text { Goats } & \text { Sheep } & \text { Donkeys } & \text { Pigs } \\ \text { Herd size } & 4.4 & 6.2 & 1.3 & 1.1 & 0.5\end{array}$

Table 2 shows an average ownership of sampled households. Hardin's thesis ('The Tragedy of the Commons) is fully operational. It can be argued that levels of stocking are determined by economic benefits/objectives than the ability of the land to support large herds or those of the community as a whole. To this end, accusations of improper tillage and detrimental stock practices alone can no longer be blamed on torrential rainfall or lack of extension staff. Ignorance and wilful neglect on the part of the farmers have a role to play.Afterally, land tenure systems has long been identified as a cause of land degradation in Zimbabwe (Chenje, Sola and Palency, 1998).

Overgrazing represents a major factor contributing to the deterioration of the land quality, ward and district's productivity of the grazing areas. The rocky nature of the ward does not quite allow the classification of land into arable and pastoral land anywhere. There is insufficient, indeed insatiable demand for arable land for use by inhabitants such that the land left is only suitable for mountain goats. Not surprisingly, a high level of erosion (gully/rill sheet wash) is evident even on gentle slopes and in fairly steeply falling areas draining into the area's rivers. Gully and rill erosion are alarming, some of them are big enough to hide a train in them. There is no doubt that overpopulation (people and livestock) is a central element in the construction of soil erosion as a problem in the ward. It can be argued that even destocking and resettlement will only be palliative and not curative.

Farmers have always practised mixed farming and maintained a large and mixed species of stock as a survival strategy. This means that nutrient cycling in the grazing areas is heavily compromised as organic matter gets transferred through ingestion of plants and gets transferred as manure from grazing areas to arable fields). Apart from that, infiltration gets seriously reduced as a result of compaction and capping hence the development of elaborative extensive gully network while browsing species are also disappearing. An increase in population means more households and homesteads. Every household has an entitlement to land yet the land is inelastic. As a copying mechanism, people are encroaching 
onto grazing land, mountain/ hill slopes, and vleis and river banks in addition to field fragmentation. Each household is rearing livestock yet grazing land is diminishing in size. Clearly, land has to cope with the ever increasing population with the result of the all too well known erosion effect. It is not an exaggeration to observe that erosion is so severe that some parts of the ward and the country (Zimbabwe) are running out of the soil. Certainly the study area falls within this category given its long, uninterrupted and unprotected slopes. Accelerated erosion owing to pressure from both humans and livestock is certainly having a telling effect. There is no denying that the immense population pressure arising from its rapid growth has taken its toll on the land. There too is evidence of declining productivity and serious river siltation in the area.

\subsection{Conservation: the way to go}

Although soil erosion is recognised as a serious problem in the country's communal areas in general and in Zaka's ward 5 in particular, there is little if at all any effort made to compensate nutrient losses and unfavourable soil properties that result from the process (Kariaga, 2000). This is as much a result of lack of resources (human and financial) as it can be that of the absence of data to show its effects on agricultural productivity. In addition, improper tillage coupled with detrimental livestock practices have a role to play in erosion in the ward. Even more importantly, ignorance, apathy and wilful neglect on the part of farmers have a role to play. Indeed, land tenure has been identified as a cause of land degradation in Zimbabwe. The lack of any adequate data base has this far curtailed the development of conservation practices to conditions in the communal lands of Zimbabwe. It reasons out therefore that the absence of data coupled with the lack of resources has hindered the rehabilitation of land necessary for the restoration of the productive capacity of the soil. There is need to understand how physical and social processes work combined or independently, then and now, if we mean to fully understand the dynamics of contemporary patterns of soil erosion. This should be understood against the background that continued soil erosion in any one location is a function not only of physical factors but also the cumulative land use decisions made by individuals within the context of their broader social, cultural, political and economic environments.

Now that cropland extension has been at the expense of rangelands, vleis and hillslopes, it means that such areas are being ploughed. On slopes and even vleis, plough furrows define water courses which eventually define gullies. Farmers are in the habit of dragging ploughs to and from their fields and in the process, they define courses which will define concentrated water flow. The problem is compounded by the non- maintenance of contour ridges where they have been 
dug or their complete absence. Even though contour ridges are known to steady or reduce runoff speed if they are correctly dug and aligned, they sadly have come to be permanently associated with forced labour (chibharo) so they have come to be fiercely resisted (carry over from the war of independence), this being the extension of 'Freedom Farming', a liberation war coinage that symbolised resistance to colonial land policies and practices. During the liberation war of the 1970's the concept of "Freedom Farming" was introduced by the freedom fighting armies. This involved destruction of existing contour ridges as a protest against the Rhodesian regime. Hence, soil conservation became a victim in a highly sensitive and indeed political debate. Now, 30 years after independence, the standard contour ridges are to some extent still 'enforced', but it is now possible to establish other means of soil conservation without actually by-passing the law.

Coupled with this, where they exist, their (contour ridges) configuration and engineering tends to promote rather than curtail soil erosion. Where they have been dug, contours typically tend to slope towards the end into vleis, small stream valleys and thus encourage concentrated flow. It is absolutely necessary to correct the sins of the past, inappropriate and exploitative cultivation, which causes serious erosion. Subsidies for controlling soil erosion, can be tried in conjunction with the improvement of extension services and farm planting.

Conservation awareness leads to mechanical measures to prevent soil erosion. In this regard, contour ridges, crop rotation and proper tillage are some of the strategies which can be employed in order to arrest the situation. At the moment, conservation in the ward, district and even country requires various measures. A basic need is to reduce population pressure though in the short-term little can be achieved via this route. Population density by far exceeds the carrying capacity of the area. Population movement from rural to urban areas is not quite a solution for this merely means transferring the problem. Zimbabwe's towns and cities are already overcrowded with very high levels of unemployment. Resettlement has been introduced as a way of decongesting rural areas. However, little has been done in the ward and district to relieve pressure. Indeed there has been 'no' movement of people from Zaka to resettlement areas. In any case, erosion is taking root in the newly resettled areas owing to the tenure system in practice there. Perhaps extending family planning services to all parts of the country could be an alternative.

Vigorous soil conservation programmes to control woodland clearance and reduce over-cultivation and overgrazing is necessary.This requires extension officers in the field and financial support from the government and external agencies. Advisory services are a necessary pre-requisite for such a programme.Unfortunately,when this was tried in more remote parts of the country,farmers remained clinging to their traditional methods. There is no harm 
though in trying this in the ward.Afterall,it is a different community,largely a different generation and the community has experienced the ravaging effects of soil erosion.Chances of the project succeeding revolve around preparing the community for action. The community should be helped to choose environmental problems to solve and to carry out the improvements. Thereafter,they should maintain and evaluate the changes.The thinking behind is that the community should feel that they 'own' the project and they become self- reliant in solving their own problems. The key to this is mobilisation of which if maintained, it increases the chances of turning early hopes into long- term change.There must be full partnership between experts/outsiders and the community which should lead to the ownership of the project.Only then can there be a real chance of lasting changes occurring and be maintained.Mobilisation of the entire community is all the more important because most of environmental improvements are at community and not individual level.Therefore it has to be ensured that the community owns the rehabilitation project and assumes full responsibility for maintaining and sustaining it from the very beginning. Unless and until this happens, the whole programme will deteriorate as lack of maintenance and dwindling interest spoil all the labour, time and expectations that would have been present at the beginning. This is particularly critical when outsiders would have left,technical experts are gone and the community is left to its own resources to use and maintain the improvement.The world is full of projects built with great enthusiasm and at great cost,which then fell into disuse months after construction was completed.Usually this is because the community felt no ownership or received inadequate training. There is need therefore to channel motivation through organising the community-'The Community Action Group'.Such a nucleus would still allow the entire community to have an input into the project activities and it will channel activity and keep the process moving .Such activities include land surveying together and pegging exercises in order to recommend the best farming practices in terms of crops and animals and also distances from rivers/streams, vleis. The propensity to hold stock in numbers irrespective of quality, far in excess of the measured carrying capacity of the area, should be tackled.Even though cattle are a status symbol, practical ways of engineering destocking should be discussed and established.

Zimbabwe has a long and politically quite shaky history of soil conservation. Construction of standardized contour ridges and drains has been enforced by governments for decades and due to enforcement, the whole idea of soil conservation has become rather unpopular among communal (African smallholder or peasant) farmers. Vetiver grass though can be planted just above the drain. The grass is a highly adaptive and fast growing such that within a season, the hedge would already be well established (Dreyer,1997). After the second 
season the drain and ridge can be destroyed giving the farmer access to more land while the field is better protected.Another conservation programme that can be introduced as an alternative type of mechanical contouring is the Fanya Juu system from Kenya. By building up bench terraces and improving moisture conservation, the system reduces soil erosion markedly compared to the standard contour ridges. There is need to try more alternatives, howeve,vetiver hedges are easy to implement and they can provide livestock fodder during the dry season.Elsewhere where it has been tried, conservation of gully catchment areas with vetiver contour hedges has proved to be much more efficient than the standard contour ridges. Later, waterways leading to gullies can be checked with vetiver, and more nurseries can be established inside the gully to provide optimum moisture conditions. The hedge traps a lot of silt thus providing for the establishment of other types of vegetation, thus further reducing the velocity of runoff thereby assisting the reclamation of gullies.

There is need to ensure sustainability and reduce dependency on purchasing the grass from commercial farms, and to achieve this, large central nurseries should be established in the ward. From there, farmers will be able to purchase planting material at a reasonable price with low transport costs or get it at no cost at all. These ward and district nurseries, when still new, will not be able to meet the high demand from farmers, who would have realized the many advantages of vetiver contour hedges. The advantages stated by the farmers are:

- less labour compared to mechanical contouring;

- improved moisture conditions leading to yield increases;

- no erosion in the fields;

- land is released for cultivation as a vetiver hedge occupies less space compared to mechanical contouring;

- availability of thatching grass from vetiver and

- snakes are repelled by the aromatic smell of vetiver grass (Dreyer,1997)

The researhers have not come across any research on the latter issue, but cobras and mambas flourish in Zaka, so if it really works, all the better. The concept of biological contouring in the form of vetiver grass barriers immediately appears strange to a farmer who has never seen it and who in the past was forced to practice mechanical contouring.

The statement of "no erosion in the fields" is related to the fact that sheet and even rill erosion are common phenomena in the fields conserved with standard contour ridges. Rill erosion mainly occurs where there are breakages in the contour ridge or where the ridge was not pegged correctly. Sheet (inter-rill) erosion does take place in fields with vetiver hedges, but it is reduced significantly due to fact that vetiver is a permeable barrier that acts like a sieve and kind of spreads runoff water right across the field and reduces the erosive velocity of run- 
off water. Thus, the total erosion and the visible signs of it in the field might be reduced, but the sedimentation of material in front of the hedge (which eventually becomes a natural terrace) proves that erosion in the field does take place. The main advantage with vetiver hedge is that soil is only transported within the field and not removed from it. Based on such positive results from the pilot sites, it can be decided to establish community nurseries in each of the 30 wards of Zaka District and at a number of schools .By just introducing vetiver grass in Zaka District, all the environmental problems described in the first section of this paper are far from solved. But vetiver hedges have proven to be a more efficient, less laborious and easily adoptable barrier against erosion compared to mechanical contouring methods like contour ridges. It looks like vetiver hedges are an almost universal and comparably cheap tool in gully reclamation. More still needs to be done in the district in order to market the idea accross the entire district or even the coutry. Pilot projects could be undertaken with soil conservation along roads, embankment stabilization and in the protection of wetlands. Vetiver grass has a high potential of being the solution to the problem of soil erosion in Zimbabwe. Efficient supervisory control is a pre-requisite for satisfactory results in soil conservation. Perhaps ,there is need to reverse the clock and restore traditional concepts of rights to land through using arable and grazing rights to individuals. This would encourage every member to be a policeman and so offences would be promptly dealt with and such awareness needs to be created among the ward community. Efficient supervisory control is a pre-requisite for satisfactory result in soil conservation. Spatial re-organisation of arable and grazing lands and settlement could be a strong basis for improved farming and conservation. This is not to say that contours should be condemmed, rather their configuration, design and engineering can be improved upon. For an example, ditches can be dug inside the contour. These would hold water and thus reduce both the volume and speed of $\mathrm{f}$ lowing water thus reducing erosion. In addition, the held water comes in handy during extended periods of little or no rainfall, mostly January. As moisture that filters into the cropland below the contour ridge replenishes moisture, so much needed by the crops, moisture stress at a very critical stage of crop development gets avoided.

\subsection{Sustainability and Potential}

Based on the above discussion, the suggested soil conservation measures have a high potential of being the solution to the problem of soil erosion in Zimbabwe. With such experiences from the ward, communal areas in many other districts stand to benefit quite a lot. Add to this the many years of experience on commercial farms, there should be no reason for the government and the many donors in Zimbabwe not to focus first of all on vetiver hedges as an alternative to 
the unpopular standard contour ridges. The grass deserves much more attention than it currently receives.

Environmentally, there is no doubt that vetiver is one of the best solutions to the conservation of arable as well as grazing land. It is easy for farmers to learn the skills related to the management of the grass. There are no expenses when first the grass is there, and the labour requirements are very low. The only concern we have in such programmes is related to the fact that Vetiveria rizanioides seems to be a clone, we do not know what diseases or pests might appear one day and within a short period, damage or even exterminate all the grass in the region. That would be an environmental disaster. But considering the worldwide experience and proof of the viability, the risk appears to be mainly theoretical. Hence, vetiver grass has a lot of potential in Zimbabwe and based on the Zaka farmers' positive response it should be worth trying on a much larger scale.

\section{Conclusions}

The findings of the analysis of the prevalence of soil erosion and its causes indicate that farmers' behaviour regarding soil conservation is a result of interplay of factors among them: physical, institutional, attitudinal and economic.

Farm size, farmers' attitudes and perceptions of causes and the severity of soil erosion, availability of draught power all have a strong bearing on soil erosion in the ward.

It is recommended that the organization of the soil conservation programmes should be more participatory and based on adequate knowledge of the intended beneficiaries so that in the end the practices introduced are more suitable to the beneficiaries. This way, higher levels of adoption of soil conservation measures can and should be achieved because there will be a sense of ownership of the project. However, it would be futile to discontinue extension services in this noble and yet desperate fight against the soil erosion scourge in the ward, district and country at large. The study also observed that there was lack of understanding of farmers' behaviour regarding soil conservation that was aggravated by the absence of a learning process that should complement a technical intervention. In view of this, it was recommended that the organization of the soil conservation programmes should be more participatory and based on adequate knowledge of the intended beneficiaries so that in the end the practices introduced are more suitable to the beneficiaries and higher levels of adoption are achieved. This way, attempts at correcting the geographical and historical myopia may be realised. 


\section{References}

Blakie,P.M.(1985)The Political Economy of Soil Erosion in Develpoing Countries.Longman ,London

Blakie,P.M. and Brookfield,H.G.(1987)Land Degradation and Society.Methuen,London

Central Statistical Office(1984) 1982 Population Census:A Preliminary

Assessment,C.S.O.,Harare.

Central Statistical Office(1994) 1992 Population Census:A Preliminary

Assessment,C.S.O.,Harare.

Central Statistical Office(2004) 2002 Population Census:A Preliminary Assessment,C.S.O.,Harare.

Chenje,M.,Sola,L. And Palency,D.(Editors)(1998) The State of Zimbabwe's

Environment.Government of Zimbabwe,Ministry of Mines ,Environment and

Tourism.Harare.

Dreyer, S. (1997). It's just like growing shallots...! Experiences with vetiver grass in a soil and water conservation programme for communal farmers in Zaka District, Zimbabwe.From http://www.vetiver.com/ZIM_zaka.htm. 8 September, 2010.

Elliot, J. (1989) "Soil Erosion and Soil Conservation in Zimbabwe"Unpublished Doctoral Thesis,Loughborough University

http:www.sardc.net/imercsa.Musokotwane Environment Resource Centre for Southern Africa.CEP FACT SHEET,SARDC (CEPF501)

Kariaga,B.M.(2000) "The effect of simulated soil erosion and fertlizer application on maize yeild" pp27-36 Geographical Journal of Zimbabwe,No.31.Harare

Kariaga,B.M.(1999) "Erosion Hazard Assessment in Western Kenya Using a Simple Gis model" pp20-30 Geographical Journal of Zimbabwe,No.31.Harare

Kureya web@step.26/11/2010

Lal, R and Singh,B.R.(1998) "Effects of soil degradatio on crop productivity in East Africa "Journal of Sustainable Agriculture,Vol 13,No.1,pp15-36

Manjoro,M. 'Understanding Farmers: Explaining Soil and Water Conservation Behaviour in Small-Holder Farmers in Southern Zimbabwe'.www.jsd-africa.com/Jsda8/4/11

Masocha ,M and Gandiwa,J.(2001) "Impacts of Mine Dumps on Vegetation structure and Plant Species Diversity in Zimbabwe:The case of Dalny Gold mine in Mashonaland West Province"pp21-32 Geographical Journal of Zimbabwe,No.32.Harare

Piementel,D.C.,Harvey,P.,Resosudarmo,K.,Sinclair,D.,Kurz,M.,Mcnair,S.,Crist,L.,Shriprit z,L.,Fitton ,R.,Saffouri,E. And Blair,R.(1997) "Environmental costs of erosion”,Science,Vol.267,pp1117-23

Rice,R.J.(1977) Fundamentals of Geomorphology.Longman,New York

Scoones, I., Chibudu C., Chikura, S., Jerenyama, P., Machaka, D., Machanja, W., Mavedzenga, 
B., Mombeshora, B., Mudhara, M., Mudziwo, C., Murimbarimba, F. and Zireza, B (1996). Hazards and Opportunities. Farming Livelihoods in Dryland Africa: Lessons from Zimbabwe. Zed Books Ltd: London.

Vincent, V. no date): Agro -ecological summary of Southern Rhodesia estimated potential arable land and Topography of European areas

Whitlow,R.J.(1988) Land Degradation in Zimbabwe A geographical Study.Report prepared on behalfb of the Department of Natural Resources,Harare 